\title{
BMJ Open Sports injuries aligned to predicted mature height in highly trained Middle- Eastern youth athletes: a cohort study
}

\author{
Abdallah Rejeb, ${ }^{1,2}$ Amanda Johnson, ${ }^{1}$ Abdulaziz Farooq, ${ }^{\circ}{ }^{3}$ Ruth Verrelst, ${ }^{2}$ \\ Samuel Pullinger, ${ }^{4}$ Roel Vaeyens, ${ }^{5}$ Erik Witvrouw ${ }^{2}$
}

To cite: Rejeb A, Johnson A, Farooq A, et al. Sports injuries aligned to predicted mature height in highly trained Middle-Eastern youth athletes: a cohort study. BMJ Open 2019;9:e023284. doi:10.1136/ bmjopen-2018-023284

- Prepublication history and additional material for this paper are available online. To view these files, please visit the journal online (http://dx.doi. org/10.1136/bmjopen-2018023284).

Received 8 April 2018 Revised 11 January 2019 Accepted 28 January 2019
Check for updates

(C) Author(s) (or their employer(s)) 2019. Re-use permitted under CC BY-NC. No commercial re-use. See rights and permissions. Published by BMJ.

For numbered affiliations see end of article.

Correspondence to Abdallah Rejeb; abdallah.rajeb@aspetar.com

\section{ABSTRACT}

Objectives To investigate the association of maturity status with injury incidence in Middle-Eastern youth athletes.

Design Prospective cohort study.

Setting Four consecutive seasons (2010-2014), Aspire Academy, Qatar.

Participants Male athletes (age range: 11-18 years) representing four disciplines enrolled and grouped into two categories: individual sports and racquet sports.

Outcome measures Injury data collected over four seasons. Athletes' anthropometric characteristics assessed to calculate age at peak height velocity. Predicted mature heights (PMHs) collected and categorised into four quartiles. Athletes had wrist and hand radiographs for assessment of skeletal age (SA). Early and late maturers with an $\mathrm{SA}$ of $>1$ year older or younger than their chronological age (CA).

Results For the sample ( $n=67$ ) across all groups, 43 (64\%) athletes had one or more injuries: total of 212 injuries, 4.9 injuries per athlete across study. Survival analysis of maturity status using SA found early maturing athletes had two-fold greater injury risk compared with late maturers (HR 2.04, 95\% $\mathrm{Cl} 1.15$ to $3.61, \mathrm{p}=0.015$ ). $\mathrm{PMH}$ associated with injury risk $(\mathrm{HR} 1.05,95 \% \mathrm{Cl} 1.01$ to $1.08, p=0.006)$. Athletes in fourth quartile $(\geq 184 \mathrm{~cm})$ had up to two-fold injury risk (HR 2.41, 95\% Cl 1.42 to 4.08 , $\mathrm{p}=0.001$ ). Racquet and individual sports involved similar injury risk (HR 1.14, 95\% $\mathrm{Cl} 0.86$ to $1.52, \mathrm{p}=0.37$ ).

Conclusion SA early maturity and PMH gradient were significant predictors of injury in youths.

\section{INTRODUCTION}

The range of somatic and biological maturity in individuals of the same chronological age (CA) is large. ${ }^{1}$ Such observations are derived from correlational and multivariate studies that compare young individuals of the same age who are at both extremes of the maturity range. ${ }^{2}$ Therefore, the assessment of maturity is an important consideration when dealing with adolescent athletes on a longitudinal basis. Further, understanding the cause of disease and injury is vital in predicting and preventing injury. ${ }^{3}$

\section{Strengths and limitations of the study}

- First longitudinal study to assess anthropometric characteristics and biological maturity status as injury risk factors in Middle-Eastern athletes.

- Participants were highly trained adolescent athletes.

- Measurement of maturity and growth were at moderate-to-high risk of bias.

- Skeletal age has major limitations in expense and minimal radiation and lack of knowledgeable staff for assessment and interpretation of results.

In young athletes, the demands of their chosen sport are superimposed on normal growth and maturation. A literature review revealed that there is a greater susceptibility to injury during certain periods of growth. ${ }^{4-6}$ Indeed, the association between an increased prevalence of injuries and the adolescent growth spurt has long been recognised. ${ }^{7-9} \mathrm{~A}$ recent study analysis ${ }^{10}$ on adolescent soccer players revealed greater risk of injury with players within age at peak height velocity (APHV) in comparison with the players before and after APHV. Mismatched rapid growth in the long bones relative to muscular lengthening may disrupt structure, neuromuscular function and physical performance. ${ }^{11}$

Deehan et $\mathrm{al}^{12}$ state that an increased participation in sports predisposes the immature skeleton to injury. Furthermore, participation in high intensity sport entails an inherent risk of sports-related injuries, and this is heightened at various stages of growth and maturation. ${ }^{13}$ Maturation induces profound changes in the skeletal, neuromuscular and tendinous systems of young athletes ${ }^{14}$ and mismatches in biological maturity may create competitive inequality and increase the risk of injury. ${ }^{15}$ Le Gall et $a l^{16}$ further point out that injury rates generally increase with increasing CA. However, $\mathrm{CA}$ is a poor indicator of biological maturity ${ }^{17}$; moreover, Ardern et $a l^{18}$ report that $\mathrm{CA}$ alone is an unreliable indicator of 
skeletal maturity. Skeletal age (SA) is generally accepted as the most accurate method of assessing biological maturity, ${ }^{6}{ }^{19}$ by identifying critical periods of development; it also offers a rational method for monitored age-specific training. Before initiating any programme for mitigating sports injuries, the magnitude of the problem must be identified and the extent of the injury defined in terms of incidence and severity. ${ }^{20}$

A number of studies have been conducted involving injuries in adolescent footballers; conversely, few studies have focused on injuries in non-footballer adolescent athletes in high performance sporting environments. ${ }^{21}$ Studies of anthropometric characteristics and biological maturity status as injury risk factors in Middle-Eastern youths are also limited, highlighting the need for more research in this area. Therefore, the purpose of the present study was to investigate injury incidence according to biological maturity using two outcome measures (SA and PHV) in highly trained youth athletes based at a Middle Eastern Sports Academy.

\section{METHODS}

Sixty-seven highly trained adolescent athletes (age range 11-18 years) representing athletics and racquet sports (table tennis and squash) from a Middle-Eastern sports school were included in this 4-year study. A prospective, longitudinal cohort design was used and included separate observation periods over four consecutive seasons (2010-2011, 2011-2012, 2012-2013 and 2013-2014), ie, school years, which lasted from the beginning of September until the end of June ( $\sim 40$ weeks). Participant maturity assessments included both anthropometric measurements, collected three times a season, and SA assessments using Fels method completed once, at the start of every season. Medical screening was performed at the beginning of each season to determine health and injury status. All selected athletes had clearance from a physician to participate in their respective sport. Written informed consent was sought and obtained from parents and assent from all participants. The study was part of a general sports science provision to the sports academy, and all procedures were reviewed and granted by the Institutional Review Board for Human Subjects and conformed to the recommendations of the Declaration of Helsinki.

\section{Participants}

Figure 1 shows the flow of participants in the study over consecutive seasons. A total of four sporting disciplines were analysed, grouped into two categories: athletics and fencing and racquet sports (squash and table tennis). This classification was based on specific sport characteristics and injury risk. ${ }^{22}{ }^{23}$ Inclusion criteria were as follows: (1) the athlete had to be enrolled in the sports school during at least one full school year; (2) athletes with injuries in previous seasons were not excluded from this study, but injuries present at the beginning of the observation period were not included in statistical analyses; and (3) injuries that were not sustained in the context of the sports programme (eg, recreational activities) or data related to sickness or other general medical conditions were not used for further analysis.

\section{Injury definition and data collection}

An injury was defined as any physical problem, which occurred during sports training, strength and conditioning training or during competition. Injuries were divided into time-loss (TL) injuries and no time-loss (NTL) injuries. A clinical examination and/or treatment of an athlete which did not result in a full training session or competition being missed was described as a

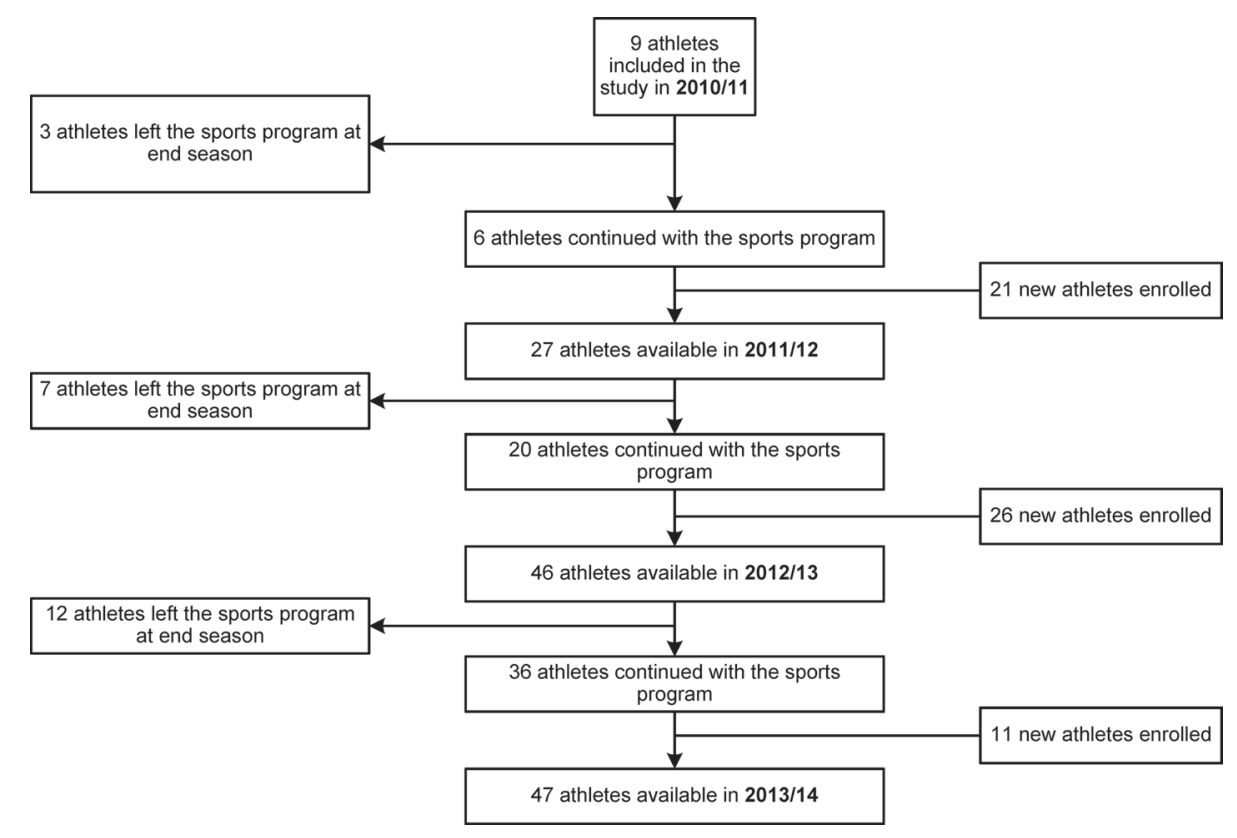

Figure 1 Flowchart describing the inclusion and flow of participants throughout the study. 
problem with NTL injury. A clinical examination and/ or treatment of an athlete resulting in a training session or competition being missed the following day(s) was labelled as a TL injury. ${ }^{23}$ A traumatic injury was defined as any injury resulting from a specific and identifiable mechanism, including contact and non-contact circumstances with acute onset. Overuse injuries were defined as injuries resulting from insidious onset without a recognisable mechanism. Injury severity was defined, based on days of absence from usual sport participation, as slight (1 day or less), minimal (2-3 days), mild (4-7 days), moderately serious (8-28 days), serious ( $>28$ days up to 6 months) or long-term ( $>6$ months) in accordance with. ${ }^{24}$

All injuries were collected by a physical therapist (AR) with experience of working within youth sport. Data from medical records were used to document all sports related injuries during the study. Each sporting discipline had a dedicated full-time physiotherapist and a full-time employed medical doctor at the sports academy. The medical record used an injury reporting system based upon the football injury reporting system ${ }^{25}$ and the Sport Medicine Diagnostic Coding System. ${ }^{26}$ Information was gathered concerning all injuries related to sports activity, including several related variables (eg, type, location, affected structure, mechanism [acute vs overuse], time loss, severity and date of injury).

\section{Somatic maturation and anthropometric measurements}

Anthropometric measurements were initially carried out on all participants on a 3-monthly basis along with an estimation of the APHV as a relative indicator of somatic maturity and representing the time of maximum growth in stature during adolescence using Mirwald method $^{27}$ for the prediction of growth. ${ }^{1}$ APHV was calculated from the first measurement recorded. To ensure that the outcome measures remained consistent and reliable, every effort was made to ensure that measurements were taken at approximately the same time of the season. Measurements were collected by qualified practitioners from the International Society for the Advancement of Kinanthropometry and included stretch stature $( \pm 0.1 \mathrm{~cm}$ Holtain Limited, Crosswell, UK).

The predicted mature height $(\mathrm{PMH})$ of all participants were collected and categorised into four PMH quartiles (Q1-Q4: Q1 $<176 \mathrm{~cm} ; 176 \mathrm{~cm} \leq \mathrm{Q} 2<180 \mathrm{~cm}$; $180 \mathrm{~cm} \leq \mathrm{Q} 3<184 \mathrm{~cm} ; \mathrm{Q} 4 \geq 184 \mathrm{~cm})$. The athletes were then divided into three maturity groups (late, normal or early maturing) based on the mean \pm 1.0 year of the APHV of the total sample (late, APHV >mean + 1.0 year; normal, APHV within mean \pm 1 .0 year; early, APHV $<$ mean -1.0 year). Years from peak height velocity (maturity offset value: CA-maturity offset) was calculated by subtracting the CA at the date of injury from the age at estimated peak height velocity.

\section{Skeletal maturation assessment}

Each year athletes were required to have a radiograph of the left wrist and hand, a convenient area to examine, and a more accurate method for the assessment of SA, ${ }^{11}$ using the Fels method ${ }^{628}$ which has an advantage over other methods. ${ }^{29}$ Maturity status, defined by the difference between CA and SA was calculated and classified into four categories: late, normal, early and mature athletes. Late referred to an SA that was younger than CA by more than 1.0 year, athletes with a normal pattern of maturity had an SA that was within 1.0 year of CA, early referred to an SA that was older than CA by more than 1.0 year and the closure of growth plate determine skeletally mature athletes.

\section{Statistical analysis}

Data were analysed usingStata 11.0 statistical software. Descriptive statistics were presented as frequencies and proportions (\%), and incidence rates were expressed as the number of injuries/number of registered athletes. To examine the role of growth status and maturity with the onset of injuries, a univariate Cox regression survival analysis was performed after accounting for repeated visits of athletes over the four seasons. HR with 95\% CIs were reported for each factor. Kaplan-Meier curves were plotted for SA groups and time to injury over a season. Where appropriate, 95\% CIs are presented. The alpha level of significance was set at $5 \%$.

\section{Patient and public involvement statement}

Patients and public were not involved in the analysis of this study.

\section{RESULTS}

Throughout the 4-year seasons study period, 67 athletes were enrolled representing 151 athletic seasons. Table 1 presents the anthropometric characteristics of participants and their maturity status. From these participants, $43(64 \%)$ reported one or more injuries adding up to 212 injuries in total. The injury rate observed per registered athlete amounted to 4.9 injuries over the course of four seasons.

Among all participants $(\mathrm{n}=67), 4 \%$ were classified as late maturers, $33 \%$ as normal, $41 \%$ as early and $22 \%$ as

Table 1 Anthropometric characteristics (mean \pm SD) of participants according to maturity status

\begin{tabular}{|c|c|c|c|}
\hline & Late & Normal & Early \\
\hline & $(n=4,6.0 \%)$ & $(n=59,88.1 \%)$ & $(n=4,6.0 \%)$ \\
\hline CA (years) & $13.3 \pm 1.1$ & $12.3 \pm 1.0$ & $12.1 \pm 0.5$ \\
\hline Years from PHV & $-2.4 \pm 1.2$ & $-1.6 \pm 1.1$ & $-0.1 \pm 0.9$ \\
\hline APHV (years) & $15.8 \pm 1.5$ & $13.9 \pm 0.5$ & $12.2 \pm 0.9$ \\
\hline $\mathrm{PMH}(\mathrm{cm})$ & $181.6 \pm 17.1$ & $179.4 \pm 4.9$ & $188.4 \pm 3.5$ \\
\hline \% PMH (\%) & $85.0 \pm 3.0$ & $85.0 \pm 4.0$ & $90.0 \pm 4.0$ \\
\hline SA (years) & $11.8 \pm 0.5$ & $12.8 \pm 1.5$ & $12.7 \pm 1.8$ \\
\hline
\end{tabular}

Skeletal age: maturity status distribution and injury risk. APHV, age at peak height velocity; CA, chronological age; $\mathrm{PMH}$, predicted mature height; $\mathrm{SA}$, skeletal age. 


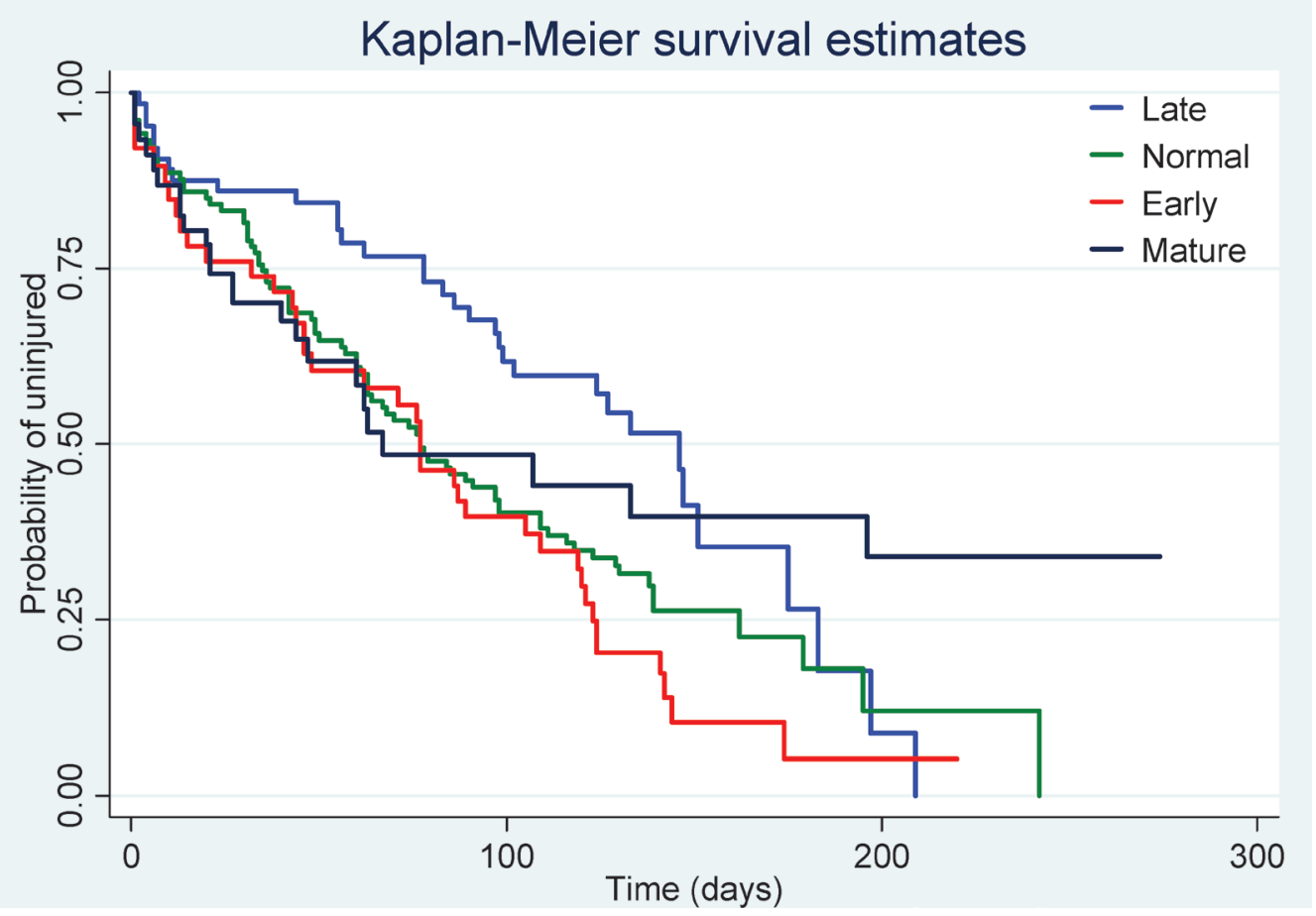

Figure 2 Kaplan-Meier survival analysis of injuries in relation to different skeletal age maturity status.

skeletally mature. The overall injury free survival analysis of maturity status using SA assessment indicated that early maturing athletes had a two-fold higher risk of injury over a season compared with late maturing athletes (HR $2.04,95 \%$ CI 1.15 to $3.61, \mathrm{p}=0.015$ ), (figure 2 ). There was a trend that early maturing athletes had a greater risk of injury over a season compared with normal athletes (HR $1.62,95 \%$ CI 0.99 to $2.65, \mathrm{p}=0.053$ ), but this was only marginally significant. However, injury risk among late and fully mature athletes did not differ from normal maturers.

\section{Somatic maturation and anthropometric measurements: distribution and injury risk}

Using anthropometric measurements, among all participants ( $\mathrm{n}=67), 6.0 \%$ were classified as late maturing, $85.8 \%$ as normal and $6.0 \%$ as early. Classification of participant maturity status (late, normal and early) according to age at PHV (APHV) was not significantly associated with overall injury incidence in this cohort of highly trained MiddleEastern youth athletes. Older PHVs were marginally associated with higher injury risk, but this was not statistically significant (HR 1.11, 95\% CI 0.99 to $1.23, \mathrm{p}=0.067$ ).

Both PMH $(\mathrm{cm})$ and \%PMH were found to be associated with injury risk (HR 1.05, 95\% CI 1.01 to 1.08 , $\mathrm{p}=0.006$, and HR 1.03 , 95\% CI 1.00 to $1.06, \mathrm{p}=0.026$ ), respectively. When compared with participants in the first quartile for PMH $(<176)$, athletes in the fourth quartile $(\geq 184 \mathrm{~cm})$ had a two and half times greater risk of injury (HR 2.41, 95\% CI 1.42 to 4.08, $\mathrm{p}=0.001$ ) over a season.

No significant differences were observed in the injury risk between racquet sports $(\mathrm{n}=30)$ and individual sports athletes $(\mathrm{n}=37$; HR 1.14, $95 \% \mathrm{CI}, 0.86$ to $1.52, \mathrm{p}=0.37)$.

\section{DISCUSSION}

The present investigation was carried out to examine injury incidence according to maturity status. Biological maturity status and height gradient play a significant role in injury risk profiles of highly trained youth athletes. The results of the current study show that athletes maturing at a younger age are at significantly greater risk of injury, more than two-fold, compared with their later maturing counterparts. Taller athletes were also found to be significantly more at risk of injury.

There is limited and contrasting evidence on the relationship between maturity and injury in youth sports. ${ }^{1030} 31$ In this study, SA maturity (Fels method) showed that early maturing athletes had twice the risk of injury over a season compared with late maturing athletes. This finding is consistent with previous study, ${ }^{6}$ that described that early maturing athletes are significantly more at risk of injury than late or normally maturing athletes. A possible explanation could be that youth players with higher engagement and performance advantages are often associated with early maturation, usually transient during adolescence, and maybe reversed in early adulthood ${ }^{16}$

However, our study results were inconsistent with other study $^{30}$ on youth athletes, in which late maturing athletes have a higher injury rate compared with their earlier maturing counterparts. A plausible explanation could be that Fourchet $e t a \vec{l}^{30}$ examined anthropometric data collected from a track and field cohort for their findings, while our study resulted from maturity status derived from bone age but with no substantial association from APHV.

In the present study, no significant association was observed between APHV and injury risk (HR 0.90, 
$95 \%$ CI 0.74 to $1.11, \mathrm{p}=0.329$ ), which is inconsistent with recent data on youth alpine ski racing ${ }^{32}$ and other studies on talented Dutch and English youth soccer players ${ }^{63}$ which show a heightened period of risk around the time of peak height velocity. An explanation of these discrepancies could be that our study cohort was not large enough, as the APHV method appears to be useful in youth talent selection and injury prevention programmes because it can be easily applied in a large cohort of young athletes. ${ }^{34}$

$\mathrm{PMH}$ and $\% \mathrm{PMH}$ at a given age are minimally invasive, feasibly practical indicators of somatic maturation, ${ }^{17} 35$ especially if mature height can be assessed without an estimate of SA. ${ }^{28}$ In this study, the PMH and \% PMH revealed that both indicators were associated with injury risk (HR $1.05,95 \%$ CI 1.01 to $1.08, \mathrm{p}=0.006$ ), and HR $1.03,95 \%$ CI 1.00 to $1.06, \mathrm{p}=0.026)$, respectively. When compared with participants in the first quartile for PMH $(<176)$, athletes in the fourth quartile $(\geq 184 \mathrm{~cm})$ had two and a half times greater risk of injury (HR 2.41, 95\% CI 1.42 to $4.08, \mathrm{p}=0.001)$. The present results are partly in line with previous studies on other sports. Johnson et at showed that gains in height in youth footballers over a season were associated with an increased number of injuries. The study of Kemper $e t a l^{36}$ on elite youth soccer players with growth rates of at least $0.6 \mathrm{~cm} /$ month showed a higher risk for injury. In a different study on soccer athletes, it was found that the tallest boys had the highest incidence of injury. ${ }^{37}$ However, these findings and those of the present study are not in line with a study on youth football players, ${ }^{38}$ in which injured and non-injured players did not differ in percentage of mature height. An explanation could be that the definition of reportable injury in the methods of the study, which considered only time loss injuries, did not capture the full spectrum of injuries and therefore overlooked other injuries with insidious onset eg, growth conditions.

The results of this study have some important practical implications. Malina $e t a t^{2}$ advocate the documentation of anthropometric characteristics, biological maturity and physical fitness parameters as crucial aids in the prevention of injury. Non-invasive methods for estimating maturity status may allow youth programmes to match players using maturity status rather than $\mathrm{CA}$, and thus equalise competition to some extent. An unequal competition is regarded as an impediment to personal development. ${ }^{39}$ Furthermore, it has been suggested that there is an overwhelming bias in sport favouring taller athletes, ${ }^{40}$ and data on Olympic medal winners show that many running and jumping events are seriously biased in favour of the very tall. ${ }^{41}$

When examining the classification resulting from SA of late $(4 \%)$, normal $(33 \%)$, early $(41 \%)$ and skeletally mature athletes $(22 \%)$, the under-representation of late and preponderance of early maturing athletes in this cohort is consistent with observations for male youth athletes in several sports including soccer and alpine ski racing. ${ }^{10} 192$ However, these results and those of the present study are not in line with the study of Johnson et at on schoolboy footballers, in which two thirds of their players fall within the normal maturity category. Moreover, Le Gall et $a l^{16}$ classify only $12.0 \%$ as late maturers, $63.5 \%$ as normal maturers, and $24.5 \%$ as early maturers. These discrepancies are believed to be due to differences in selection policies and talent identification policies (physical, technical and tactical skills) of varying elite development centres. Several studies point out that athletes who are more advanced in their biological maturity perform better than their later maturing peers and have a better chance of being selected. ${ }^{42-44}$ Youth sport is highly selective, with a maturity-associated selection/ exclusion process. ${ }^{35}$

\section{Implications and concepts for prevention}

The findings in this study have several implications for youth athletes. First, our data suggest that adolescent athletes might be identified and selected with a preference for youths with advanced maturity. Such selection strategies which favour early maturers entail significant risks of injury. Accordingly, those involved in the selection and development of young athletes should be cognizant of temporary changes in motor control that may occur during these periods, ${ }^{45}$ consider maturity status, develop appropriate training programmes to optimise training adaptation, design injury prevention plans to minimise activity related injury risk and mitigate long term youth injury consequences.

Limitations of the current study should be noted. First, biological maturation methods have inherent limitations when applied to youth athletes and need to be applied with caution. Although SA is a gold standard indicator of maturation, it has major limitations in expense and minimal radiation and lack of knowledgeable staff for assessment protocols and the interpretation of results. ${ }^{46}$ Although our sample size is small, we have a follow-up over four seasons. Another limitation, we had no data on training or competition exposure, which reduces the comparability with other studies reporting injury incidence.

It must also be remembered that, except for accidents, a sports injury can rarely be ascribed to a single factor, but rather to an association of causes or circumstances and the interaction among a web of determinants. ${ }^{478}$

\section{CONCLUSIONS}

The findings of the present study showed that maturity status plus $\mathrm{PMH}$ and \% $\mathrm{PMH}$ are associated with injury in individual and racquet sports but no association has been established between APHV and injury. As SA varies individually in rate and timing, and mismatches in maturity may create competitive inequality and increase injury incidence, it is suggested that biological maturity should be considered during training to help prevent injury. Given the peculiarity of youth athletes it is important to optimise the planning of training activities to further 
improve the understanding of the link between training, growth and injury.

\section{Author affiliations}

${ }^{1}$ Aspire Academy Sports Medicine Center, Aspetar Qatar Orthopaedic and Sports Medicine Hospital, Doha, Qatar

${ }^{2}$ Rehabilitation Sciences and Physiotherapie, Universiteit Gent Faculteit Geneeskunde en Gezondheidswetenschappen, Gent, Belgium

${ }^{3}$ Athlete Health and Performance Research, Aspetar, Orthopaedic and Sports Medicine Department, Doha, Qatar

${ }^{4}$ Department of Sports Sciences, ASPIRE Academy for Sports Excellence, Doha, Ad Dawhah, Qatar

${ }^{5}$ Department of Movement and Sports Sciences, Universiteit Gent Faculteit Geneeskunde en Gezondheidswetenschappen, Gent, Belgium

Acknowledgements The publication of this article was funded by the Qatar National Library.

Contributors AR designed and developed the research question and wrote the original version of the manuscript as part of his doctoral thesis. EW (doctoral supervisor) reviewed, designed and provided expertise to the study. AJ (doctoral committee member) was involved in study design. AF supervised and provided expertise with respect to the data analyses. RVe, SP and RVa (doctoral committee member) reviewed and provided expertise to the study. All authors have contributed to and edited the manuscript and have approved the final manuscript.

Funding The authors have not declared a specific grant for this research from any funding agency in the public, commercial or not-for-profit sectors.

Competing interests None declared.

Patient consent for publication Parental/guardian consent obtained.

Provenance and peer review Not commissioned; externally peer reviewed.

Data sharing statement No additional data are available.

Open access This is an open access article distributed in accordance with the Creative Commons Attribution Non Commercial (CC BY-NC 4.0) license, which permits others to distribute, remix, adapt, build upon this work non-commercially, and license their derivative works on different terms, provided the original work is properly cited, appropriate credit is given, any changes made indicated, and the use is non-commercial. See: http://creativecommons.org/licenses/by-nc/4.0/.

\section{REFERENCES}

1. Iuliano-Burns S, Mirwald RL, Bailey DA. Timing and magnitude of peak height velocity and peak tissue velocities for early, average, and late maturing boys and girls. Am J Hum Biol 2001;13:1-8.

2. Malina RM, Cumming SP, Morano PJ, et al. Maturity status of youth football players: a noninvasive estimate. Med Sci Sports Exerc 2005;37:1044-52.

3. Meeuwisse W. Assessing causation in sport injury: a multifactorial model. Clin J Sport Med 1994;4:166-70.

4. Krivickas LS, Feinberg JH. Lower extremity injuries in college athletes: relation between ligamentous laxity and lower extremity muscle tightness. Arch Phys Med Rehabil 1996;77:1139-43.

5. Aicardi G, Vignolo M, Milani S, et al. Assessment of skeletal maturity of the hand-wrist and knee: A comparison among methods. Am J Hum Biol 2000;12:610-5.

6. Johnson A, Doherty PJ, Freemont A. Investigation of growth, development, and factors associated with injury in elite schoolboy footballers: prospective study. BMJ 2009;338:b490.

7. Peterson HA. Epiphyseal growth plate fractures. 2007.

8. Bailey DA, Wedge JH, McCulloch RG, et al. Epidemiology of fractures of the distal end of the radius in children as associated with growth. J Bone Joint Surg Am 1989;71:1225-31.

9. Leppänen $\mathrm{M}$, Pasanen $\mathrm{K}$, Clarsen $\mathrm{B}$, et al. Overuse injuries are prevalent in children's competitive football: a prospective study using the OSTRC Overuse Injury Questionnaire. Br J Sports Med 2018:bjsp orts-2018-099218.

10. Materne $\mathrm{O}$, Farooq $\mathrm{A}$, Johnson $\mathrm{A}$, et al. Relationship between injuries and somatic maturation in highly trained youth soccer players: Int Res Sci Soccer II, 2016:182-92.

11. Lloyd RS, Oliver JL, Faigenbaum AD, et al. Chronological age vs. biological maturation. J Strength Cond Res 2014;28:1454-64.
12. Deehan DJ, Bell K, McCaskie AW. Adolescent musculoskeletal injuries in a football academy. J Bone Joint Surg Br 2007;89:5-8.

13. Read $P$, Oliver JL, De Ste Croix MBA, et al. Injury risk factors in male youth soccer players. Strength Cond J 2015;37:1-7.

14. Mersmann F, Bohm S, Arampatzis A, et al. Imbalances in the development of muscle and tendon as risk factor for tendinopathies in youth athletes: a review of current evidence and concepts of prevention. Front Physiol 2017;8:1-18.

15. Cumming SP, Brown DJ, Mitchell S, et al. Premier League academy soccer players' experiences of competing in a tournament biobanded for biological maturation. J Sports Sci 2018;36:757-65.

16. Le Gall F, Carling C, Reilly T. Biological maturity and injury in elite youth football. Scand J Med Sci Sports 2007;17:564-72.

17. Beunen GP, Rogol AD, Malina RM. Indicators of biological maturation and secular changes in biological maturation. Food Nutr Bull 2006;27:S244-S256.

18. Ardern CL, Ekås G, Grindem H, et al. 2018 International Olympic Committee consensus statement on prevention, diagnosis and management of paediatric anterior cruciate ligament $(A C L)$ injuries. Knee Surgery, Sport Traumatol Arthrosc 2018;0:1-17.

19. Malina RM. Early sport specialization: roots, effectiveness, risks. Curr Sports Med Rep 2010;9:364-71.

20. Leppänen $M$, Lapinleimu $\mathrm{H}$, Lehtonen $\mathrm{L}$, et al. Growth of extremely preterm infants born in 2001-2010. Acta Paediatr 2013;102:206-8.

21. Steffen K, Engebretsen L. More data needed on injury risk among young elite athletes. Br J Sports Med 2010;44:485-9.

22. Rejeb A, Johnson A, Vaeyens R, et al. Compelling overuse injury incidence in youth multisport athletes. Eur J Sport Sci 2017; 17:495-502.

23. Malisoux L, Frisch A, Urhausen A, et al. Injury incidence in a sports school during a 3-year follow-up. Knee Surgery, Sports Traumatology, Arthroscopy 2013;21:2895-900.

24. Timpka T, Alonso JM, Jacobsson J, et al. Injury and illness definitions and data collection procedures for use in epidemiological studies in Athletics (track and field): consensus statement. Br J Sports Med 2014:48:483-90.

25. Fuller CW, Ekstrand J, Junge $A$, et al. Consensus statement on injury definitions and data collection procedures in studies of football (soccer) injuries. Scand J Med Sci Sports 2006;16:83-92.

26. Meeuwisse WH, Tyreman $\mathrm{H}$, Hagel B, et al. A dynamic model of etiology in sport injury: the recursive nature of risk and causation. Clin J Sport Med 2007;17:215-9.

27. Mirwald RL, Baxter-Jones AD, Bailey DA, et al. An assessment of maturity from anthropometric measurements. Med Sci Sports Exerc 2002;34:689-94.

28. Khamis HJ, Roche AF. Predicting adult stature without using skeletal age: the Khamis-Roche method. Pediatrics 1994;94:504-7.

29. Silventoinen K, Pke M, Tynelius P. Muscle strength and body size and later cerebrovascular and coronary heart disease maturity status and injury risk in youth soccer players. Sport Med 2010;20:131-5.

30. Fourchet $\mathrm{F}$, Horobeanu $\mathrm{C}$, Loepelt $\mathrm{H}$, et al. Foot, ankle, and lower leg injuries in young male track and field athletes. International Journal of Athletic Therapy and Training 2011;16:19-23.

31. Swain M, Kamper SJ, Maher CG, et al. Relationship between growth, maturation and musculoskeletal conditions in adolescents: a systematic review. Br J Sports Med 2018;52:1246-52.

32. Müller L, Hildebrandt $\mathrm{C}$, Müller $\mathrm{E}$, et al. Long-term athletic development in youth alpine ski racing: the effect of physical fitness, ski racing technique, anthropometrics and biological maturity status on injuries. Front Physiol 2017;8.

33. Vanderlei FM, Vanderlei LC, Bastos FN, et al. Characteristics and associated factors with sports injuries among children and adolescents. Braz J Phys Ther 2014;18:530-7.

34. Müller L, Müller E, Hildebrandt $\mathrm{C}$, et al. [The assessment of biological maturation for talent selection - which method can be used?]. Sportverletz Sportschaden 2015;29:56-63.

35. Bergeron MF, Mountjoy M, Armstrong N, et al. International olympic committee consensus statement on youth athletic development. $\mathrm{Br} \mathrm{J}$ Sports Med 2015;49:843-51.

36. Kemper GL, van der Sluis A, Brink MS, et al. Anthropometric injury risk factors in elite-standard youth soccer. Int J Sports Med 2015;36:1112-7.

37. Backous DD, Friedl KE, Smith NJ, et al. Soccer injuries and their relation to physical maturity. Am J Dis Child 1988;142:839-42.

38. Malina RM, Morano PJ, Barron M, et al. Incidence and player risk factors for injury in youth football. Clin J Sport Med 2006;16:214-22.

39. Musch J, Grondin S. Unequal competition as an impediment to personal development: a review of the relative age effect in sport. Developmental Review 2001;21:147-67.

40. Baxter-Jones AD. Growth and development of young athletes. Should competition levels be age related? Sports Med 1995;20:59-64. 
41. Khosla T. Unfairness of certain events in the Olympic games. Br Med J 1968;4:111-3.

42. Beunen GP, Malina RM, Van't Hof MA, et al. Adolescent Growth and Motor Performance, 1988.

43. Philippaerts RM, Vaeyens $\mathrm{R}$, Janssens $\mathrm{M}$, et al. The relationship between peak height velocity and physical performance in youth soccer players. J Sports Sci 2006;24:221-30.

44. Malina RM, Bouchard C, Bar-Or O. Growth, maturation, and physical activity. Growth Matur Phys Perform 2004:1-17.

45. Mueller L, Hildebrandt C, Mueller E, et al. Injuries and illnesses in a cohort of elite youth alpine ski racers and the influence of biological maturity and relative age: a two-season prospective study. Open Access J Sport Med 2017;8:113-22.

46. Malina RM, Rogol AD, Cumming SP, et al. Biological maturation of youth athletes: assessment and implications. Br J Sports Med 2015;49:852-9.

47. Theisen D, Malisoux L, Seil R, et al. Injuries in youth sports: epidemiology, risk factors and prevention. Dtsch Z Sportmed 2014;65:S248-52.

48. Bittencourt NFN, Meeuwisse WH, Mendonça LD, et al. Complex systems approach for sports injuries: moving from risk factor identification to injury pattern recognition-narrative review and new concept. Br J Sports Med 2016;50:1309-14. 